\title{
Prevalence of Cigarette Smoking among Medical Iraqi Students
}

\author{
Fady S. Yasso ${ }^{1, *}$, Saba S. Yaso ${ }^{2}$, Petra S. Yasso ${ }^{3}$, Isam V. Dafdony ${ }^{4}$ \\ ${ }^{1}$ Detroit Medical Center, Detroit, MI, USA \\ ${ }^{2}$ Former Instructor, College of Medicine, University of Baghdad, Iraq \\ ${ }^{3}$ Former Instructor, College of Medicine, Al-Mustansiriya University, Baghdad, Iraq \\ ${ }^{4}$ Departments of Pediatrics, Albert Einstein Medical Center, Philadelphia, PA, USA \\ *Corresponding author: fadyyasso@yahoo.com
}

Received November 26, 2013; Revised December 30, 2013; Accepted January 03, 2014

\begin{abstract}
The researcher performed this cross sectional study at three different medical colleges in Baghdad during the period June 2005 to June 2006. The aim of this research was to study the prevalence of cigarette smoking among students from different colleges of medicine in Baghdad as well as studying some of the factors associated with smoking habit. The study included 500 medical students, from them, 198 were females and 302 were males. The researchers achieved data collection by using a questionnaire form. The survey dealt with various parameters including age, gender, family member smoking habit and self-reported cause of smoking. This paper reveals that the prevalence of cigarette smoking among medical students is (21\%); about $42 \%$ of them started smoking at $18-19$ years age or their first year of medical school. Although most of them knew that smoking is harmful, they did not wish to quit smoking. The study concluded that almost all smokers were males. There was no association between the smoking habit of family members and the smoking habit of medical students. The most common three causes of cigarette smoking reported by the students were entertainment(22.1\%) followed by stress and stress relieves (18.3\%) then anxiety \& emotional causes (11.5\%).The research team did a comparison of the present study with various international studies; and discussed both agreement and disagreements thoroughly.
\end{abstract}

Keywords: lung cancer, medical students, medical school, respiratory disease, smoking, stress

Cite This Article: Fady S. Yasso, Saba S. Yaso, Petra S. Yasso, and Isam V. Dafdony, "Prevalence of Cigarette Smoking among Medical Iraqi Students.” American Journal of Public Health Research 2, no. 1 (2014): 10-15. doi: 10.12691/ajphr-2-1-3.

\section{Introduction}

Smoking is the main cause of preventable death [8]. Cigarettes, pipes, hookas and other modes of smoking are very common among all adults. About 44 million adult smokes in the US [7], although both men and women smoke, men usually report higher prevalence of smoking [7]. Cigarette smoking causes about 440,000 deaths annually in the US $[9,10,25]$. In 2010, a study reported that smoking prevalence in the US was highest in the Midwest states (21.8\%) and Southern states (21.0\%); western states reported the lowest prevalence in the US (15.9\%) [11]. Some variations in the prevalence of smoking was observed among different ethnic groups, CDC reported that in year 2011: smokers were 31.5\% non-Hispanic American Indian/Alaska Native, 27.4\% nonHispanic multiple race, $20.6 \%$ non-Hispanic white, $19.4 \%$ non-Hispanic black, 12.9\% Hispanic, 9.9\% non-Hispanic Asian [13]. It is worth mentioning that minors in the US (under 18 year of age) smokes too as reported by Silverstein et al [22]. About 4,000 minors start their first cigarette daily, and about 1,000 minors become a daily cigarette smoker [19,24].
Cigarette and other modes of smoking causes lung cancer and respiratory diseases. These facts have been concluded by hundreds of studies [12,23], and still the tobacco industry says the results are flawed.

Abdul Fatah [2] presented a report that discussed how other factors could be of importance when dealing with smoking. The presence of anti-smoking movements as well as the continuous cigarette price increases prevented 600,000 teens from taking up smoking in the US. In 1979, a US memorandum noted, "Marlboro dominates in the 17 and younger age category”. Abdul Fatah [2] reported that in 1978the memorandum stated, "The base of our business is the high school students”. Unfortunately, studies paid a very small attention, if any, to the smoking habit among medical students in Iraq. Bearing in mind that medical students are the future physicians, those future physicians are responsible to educate their own patients toward quitting cigarette smoking. Accordingly, it is necessary for the present study to focus the attention on this important issue in Iraq.

\section{Morbidity and Mortality Associated with Smoking}


Cigarette smoke contains over 4,800 chemicals, from them; at least sixty-nine chemicals cause cancer. Cigarette smoking causes approximately $90 \%$ of lung cancer deaths and about $85 \%$ of chronic obstructive pulmonary diseases deaths such as emphysema and chronic bronchitis deaths.

Smoking is associated with wide spectrum of diseases like cancers, cardiovascular diseases, strokes, and pulmonary diseases [12,14,23]. Smokers die at an earlier age than non-smokers do. Jha et al reported an average of 10 years early death in smokers [17].

Smoking does not only cause illnesses, but also a financial burden. During the period, 2000-2004, the loss of potential productive years as well as health care cost in the US was approximately $\$ 193$ billion [9]. El-Ansari [15] reported that smoking also affects second hand smokers, accordingly an extra financial burden will result, and Behan et al [3] reported $\$ 10$ billion loss due to health care expenditure, morbidity \& mortality in secondhand smokers.

A study by Najdawi and Faouri [18], suggested that smoking had a direct effect on breastfeeding. The prevalence of breastfeeding reduced significantly among smokers but there was no significant reduction among non-smokers.

Antismoking movements plays an important role in educating the population about the product that kills more Americans than AIDS, alcohol, road traffic accidents, homicides, suicides, illegal drugs, and fires together, the law cannot be too strict. Education that when you see tobacco advertisements, or you are to choose whether to smoke or not, remember that tobacco companies are greedy money-grubbers [2].

\section{Cigarette Smoking among Medical Students}

Despite their knowledge about smoking as well as seeing patients and death cases during their training, medical students as well as physicians smoke. Coe and Cohen [6] as well as Birkneret al. [4] reported that $14 \%$ of medical students smoke in the US.

Prevalence of smoking among medical students varies internationally. A study by Smith and Leg gat [21] showed that Australia and the United States had lower smoking rate among their medical students, while Spain and Turkey reported much higher rates. A study by Abdulghani et al [1] showed that $4.3 \%$ of females who are medical school students smoke in Saudi Arabia. Xinguang et al [29] reported that $66.9 \%$ of males and $26 \%$ of females who are medical students in China smoked cigarettes. A study in Iran medical schools by Nazary et al [19] showed the prevalence of smoking was $14.4 \%$ among medical students.

\section{Collection of Data}

A cross sectional study was carried out in different medical schools in Baghdad, Iraq namely (University of Baghdad, Al-Mustansiriya University and Al-Nahrain University). The research team performed the study during the period of June 2005 to June 2006. Participating medical schools granted the ethical clearance and IRB approval of this study, after which the research team allowed the authors to perform the survey.

For the data to be reliable, and for the sample to provide a proper representation, the sample covered different age groups, different genders, race, occupation, etc. Accordingly, the study included 500 consenting medical students. The research team designed a specific questionnaire, the authors then distributed it to medical students in their schools, worship places, community and young adults' centers. Of those, there was 198 female \& 302 male participants.

The research team then did the data collection using the questionnaire form, the survey dealt with various parameters including, age, gender, no. of cigarettes smoked per day, onset of smoking, family members smoking habits \& cause of smoking.

After explaining the method of filling the questionnaire form to the students, the interviewing author distributed the questionnaire form among the students \& they filled the forms. The authors replaced the students' names by codes to protect the student's privacy.

The authors used Microsoft Excel to make spreadsheets, tables, graphs, and figures. The research team used SPSS statistics 21 to perform data analysis. For categorical variables, the authors used Chi square test.

\section{Analysis of Collected Data}

Table 1 presents the relationship between gender and the prevalence of smoking among medical students at three different colleges of medicine in Baghdad, namely, the University of Baghdad, Al-Mustansiriya University and Al-Nahrain University.

Table 1. Prevalence of Smoking among Medical Students by Gender
\begin{tabular}{|c|c|c|c|}
\hline \multirow{2}{*}{ Gender } & \multicolumn{2}{|c|}{ Do you smoke? } & \multirow{2}{*}{ Total } \\
\cline { 2 - 3 } & Yes & No & \\
\cline { 2 - 3 } Male & 101 & $\begin{array}{c}209 \\
67.4 \%\end{array}$ & \multirow{2}{*}{310} \\
\hline \multirow{2}{*}{ Female } & $32.6 \%$ & 187 & \multirow{2}{*}{190} \\
& $1.6 \%$ & $98.4 \%$ & \\
\hline \multirow{2}{*}{ Total } & 104 & 396 & 500 \\
& $20.8 \%$ & $79.2 \%$ & \\
\hline
\end{tabular}

It is obvious from this table that the number of female smokers is very low (1.6\%) as compared to $32.6 \%$ for males. This difference is statistically significant with a pvalue of 0.000 using Chi square test. To explain the observed difference, it is necessary to note that the number of female medical students is generally less than those of the male students and those female students do not like to smoke socially due to cultural variations. However, it is interesting to note that the majority of students (79.2\%), especially females, are non-smokers.

In Iraq, medical students start their first year medical school after high school immediately (age of 18-19 years old), for a medical student to graduate, it takes at least 6 year. Most students graduate at the age of 23-24. Those who fail one or more years of their medical school might graduate at the age of 25-26. 
Figure 1. Shows the age distribution among the sample studied. Most student started smoking at their first year of medical school at the age 18-19. Others started smoking later in their years of medical school. From the 104 smoking student interviewed, forty four (42.31\%) started smoking at the their first year of medical school which is the age of 18-19, twenty four student (23.08\%) started smoking at their second year of medical school which corresponds to the age 19-20 years old. Sixteen (15.4\%) medical student started smoking at the age 20-21, eight students (7.7\%) started smoking at the age 21-22, seven students $(6.7 \%)$ started smoking at the age 22-23, three students (2.8\%) started smoking at the age 23-24, one $(0.96 \%)$ started smoking at the age $24-25$ and one $(0.96 \%)$ started smoking at the age 25-26 years old.

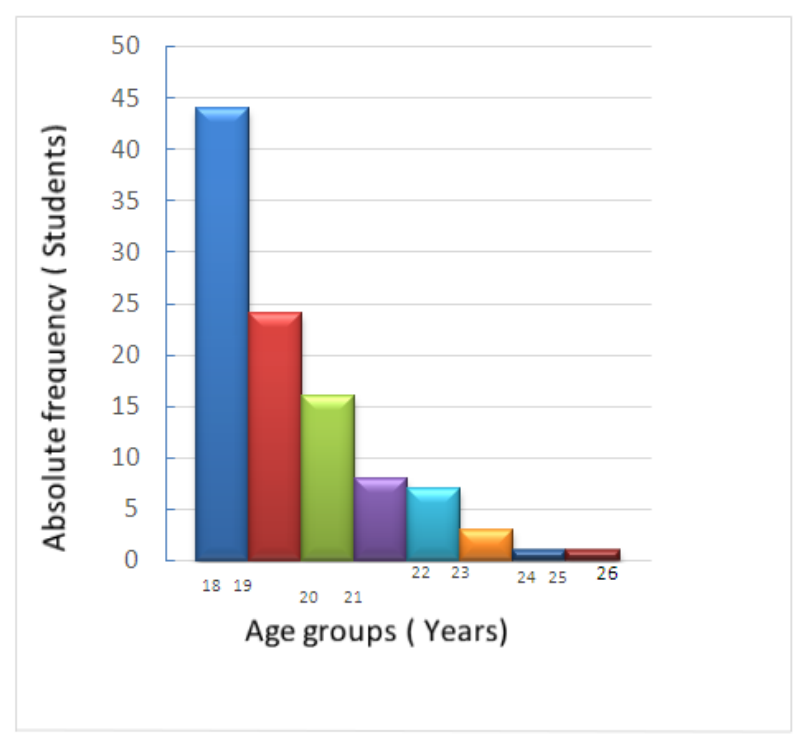

Figure 1. Cigarette smoking age of onset

Figure 2 deals with the daily number of cigarettes smoked by the medical students interviewed. From the 104 smoking students, 60 smoked 1-10 cigarettes daily (57.7\%), 35 smoked 11-20 cigarettes daily (33.7\%) and 9 smoked more than 20 cigarette per day (8.6\%).

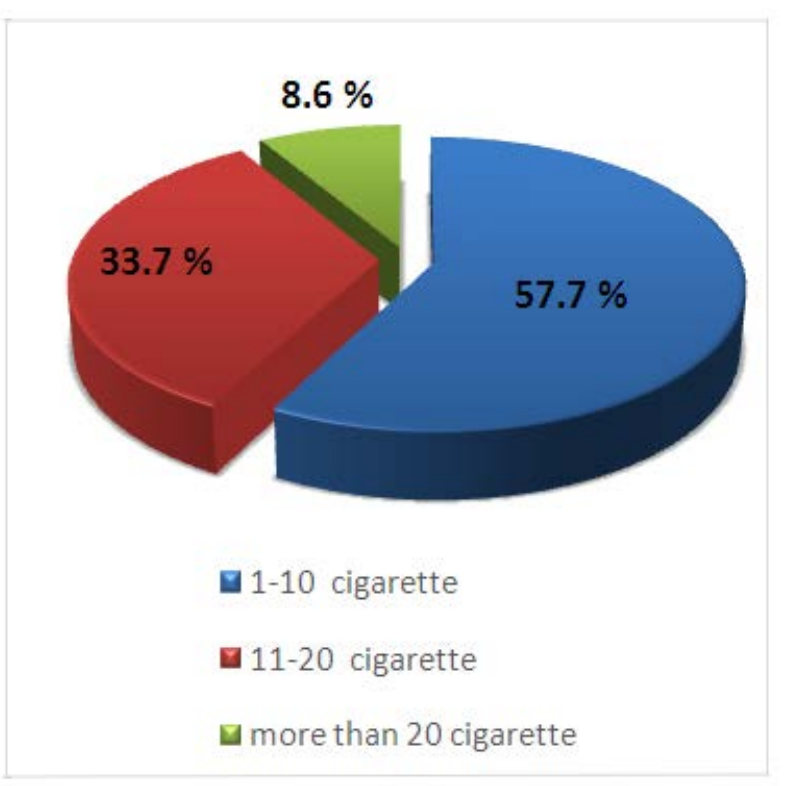

Figure 2. Percentage of smokers for different daily number of cigarettes
It is obvious that $57.7 \%$ of smoking students smoke 1 to 10 cigarettes daily, while only $33.7 \%$ of the smoking students smoke between 11 and 20 cigarettes daily. Heavy smokers with more than 20 cigarettes daily have rather low percentage of $8.6 \%$.

Table 2 presents the relationship between smoking / non-smoking fathers, and the prevalence of smoking among medical students.

Table 2. Prevalence of Smoking among Students having Smoking / Non-smoking Fathers

\begin{tabular}{|c|c|c|c|}
\hline \multirow{2}{*}{ Do you Smoke? } & \multicolumn{2}{|c|}{$\begin{array}{c}\text { Smoking habit } \\
\text { of mother }\end{array}$} & \multirow{2}{*}{ Total } \\
\hline & Smoker & Non smoker & \\
\hline Yes & $\begin{array}{c}12 \\
11.5 \%\end{array}$ & $\begin{array}{c}92 \\
88.5 \%\end{array}$ & $\begin{array}{c}104 \\
100 \%\end{array}$ \\
\hline No & $\begin{array}{c}32 \\
8.1 \%\end{array}$ & $\begin{array}{c}364 \\
91.9 \%\end{array}$ & $\begin{array}{c}396 \\
100 \%\end{array}$ \\
\hline Total & $\begin{array}{c}44 \\
8.4 \%\end{array}$ & $\begin{array}{c}456 \\
91.6 \%\end{array}$ & $\begin{array}{c}500 \\
100 \%\end{array}$ \\
\hline
\end{tabular}

It is obvious that for smoking medical students, there was no difference whether they had a smoking father or not. However, Chi-square test showed a significant difference among those students who did not smoke with a p-value of 0.02 . About $60 \%$ of them had a non-smoking father.

Similarly, Table 3 shows the effect of smoking / nonsmoking mother on the prevalence of smoking among students.

Table 3. Prevalence of Smoking among Students having Smoking /Non-smoking Mothers

\begin{tabular}{|c|c|c|c|}
\hline \multirow{2}{*}{ Do you smoke? } & \multicolumn{2}{|c|}{ Smoking habit of father } & \multirow{2}{*}{ Total } \\
\cline { 2 - 3 } & Smoker & Non-Smoker & \\
\hline \multirow{2}{*}{ Yes } & 53 & 51 & 104 \\
& $51 \%$ & $49 \%$ & $100 \%$ \\
\hline No & 154 & 242 & 396 \\
& 38.7 & $61.3 \%$ & $100 \%$ \\
\hline & & & \\
Total & 207 & 293 & 500 \\
& $41.4 \%$ & $58.6 \%$ & $100 \%$ \\
& & & \\
\hline
\end{tabular}

It is obvious that for smoking medical students, most of them had non-smoking mothers. About $92 \%$ of those who did not smoke had a non-smoking mother too. Chi-square showed that the difference among those who smoke and those who did not smoke is statistically insignificant with a p-value 0.268 .

\section{Causes of Smoking among Medical Students}

One of the most important results obtained from this research is the cause of smoking among medical students in Baghdad. The Pei chart of Figure 3 shows that the most common and serious causes of smoking among medical students are stress, sadness \& depression, anxiety and emotional (39.4\% combined), while $22.1 \%$ reported that 
they smoke for entertainment. On the other hand, about $26 \%$ of those students were unsure why they are smoking.

\section{$2.90 \%$}
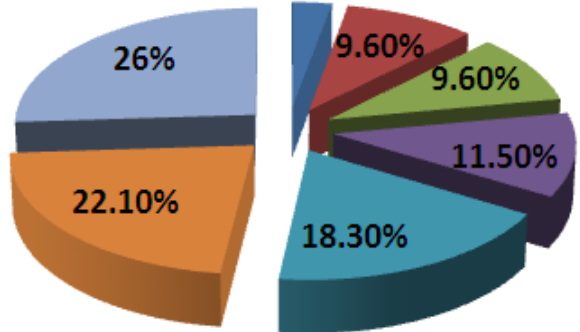

- Unsuccessfulness

- Surrounding environment

- Sadness \& Depression

- Anxiety \& emotional

- Stress \& stress relieve

Entertainment

Unknown

Figure 3. Causes of smoking among Iraqi medical students

\section{Discussion \& Comparison with Other Studies}

Smoking among medical students is common.This study showed that $20.8 \%$ of medical students smoke cigarette. This percentage is in agreement with the study in China by Xinguang [29], Foley et al [16] and Thomas [27] who reported smoking prevalence among medical students as $28.1 \%, 23 \%$ and $31 \%$ respectively. Other studies like Udall [26], Purvis \& Smith [28], Birkner \& Kunze [4], and Coe \& Cohen [6] reported much lower rates like $13 \%, 12 \%, 14 \%$ and $6 \%$ respectively.

This study showed that about $58 \%$ of the students consumed 1-10 cigarette / day; while Nazary et al study, [18] showed that about $89.1 \%$ of the students consumed less than 10 cigarettes per day.

Various factors contribute and motivate medical students to smoke such as entrainment, stress, depression etc. This study showed that about $26 \%$ of the students were unsure of the cause of their smoking habit. The most reported causes in this study were entertainment, stress and stress relieve, anxiety and emotional causes.

A study in China by Xiang et.al. [30], showed that the major reasons for smoking among medical students were Stress (42.8\%), Curiosity (34.4\%), and loneliness (33.7\%) as shown in Table 4 and Figure 4.

\begin{tabular}{|c|c|c|c|c|c|c|c|c|}
\hline \multirow{2}{*}{ Country / city } & \multicolumn{2}{|c|}{ Medical students' prevalence of smoking } & \multicolumn{5}{|c|}{ Contribution of major reasons to Medical students' smoking } & \multirow{2}{*}{ Reference Code } \\
\hline & Males & Females & Stress & Curiosity & Loneliness & Entertainment & Others & \\
\hline Iraq / Baghdad & $32.6 \%$ & $1.6 \%$ & $18.3 \%$ & $26 \%$ & $9.6 \%$ & $22.1 \%$ & $24 \%$ & Present Study \\
\hline $\begin{array}{c}\text { Saudi Arabia / } \\
\text { Riyadh }\end{array}$ & $\mathrm{N} / \mathrm{A}$ & $0.86 \%$ & $\mathrm{~N} / \mathrm{A}$ & $\mathrm{N} / \mathrm{A}$ & $\mathrm{N} / \mathrm{A}$ & $54 \%$ & $44.4 \%$ & [1] \\
\hline China / Wuhan & $37.7 \%$ & $0 \%$ & $42.8 \%$ & $34.4 \%$ & $33.7 \%$ & $\mathrm{~N} / \mathrm{A}$ & $\mathrm{N} / \mathrm{A}$ & [30] \\
\hline
\end{tabular}

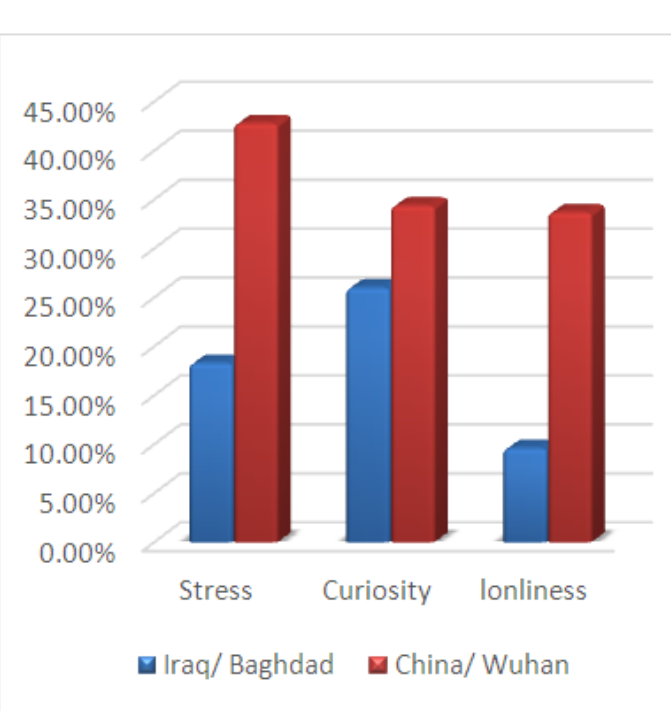

Figure 4. Comparison of causes of smoking among Iraqi and Chinese medical students

It is apparent from Table 4 that there are common causes of cigarette smoking between the different studies.
Based on this fact, Figure 4 shows a comparison of causes of smoking among Iraqi and Chinese medical students, while Figure 5 is devoted to Iraqi and Saudi Arabia medical students.



Figure 5. Comparison of causes of smoking among Iraqi and Saudi Arabia medical students 
It is obvious from Figure 4 that Chinese medical students use smoking as a way to overcome their stress \& loneliness as compared to Iraqi medical students. Some Chinese medical students were just curious to try what smoking habit feels, and then they became a daily smoker.

Although both Iraqi and Saudi Arabia medical students reported entertainment as a cause of smoking for their smoking habit, a study by Abdulghani et al [1] showed that entertainment was the leading cause of smoking among Saudi Arabia medical students as shown in Table 4 and Figure 5.

This difference might be due to the facts that Abdulghani et al [1] study was restricted to females medical students only.

The present study showed a sensible difference in the prevalence in relation to gender. Smoking prevalence in males is $32.6 \%$ and $1.6 \%$ among females. The low prevalence of smoking among females medical students is in agreement with the study done in Saudi Arabia by Abdulghani et at [1], who showed that the prevalence of cigarette smoking among females medical students was $4.3 \%$. On the other hand, a high rate $(17.6 \%)$ of smoking females medical student was found in studies in countries like Germany as reported by Brenner and Scharrer [5].

\section{Conclusions and Recommendations}

The conclusions and recommendations of this work are as follows.

(1) The majority of Baghdad, Iraq medical students (79.2\%), especially females, are non-smokers.

(2) The low prevalence of smoking among Iraqi female medical students $(1.6 \%)$ is in agreement with the $(4.3 \%)$ in Saudi Arabia and 0\% in China, but in disagreement with the high prevalence (17.6\%) in Germany.

(3) The main reported causes of smoking among medical students in the present study appear to be entertainment (23\%), stress (14\%) and (27\%) did not know the cause of their smoking (unknown cause). The rest (36\%) includes stress relieve, anxiety, emotional, etc.

(4) High percentage $(57.7 \%)$ of smoking Iraqi students, smoke 1-10 cigarette daily, while only $33.7 \%$ of the smoking students smoke between 11-20 daily.

(5) Heavy smokers who smoke more than 20 cigarettes / day in this study comprise only $8.6 \%$.

(6) The mean number of cigarette / day / smoker was 10.5 .

(7) The presence of a non-smoking father affects the prevalence of smoking in their offspring. While the smoking habit of the mother has no significant effect on the student's smoking habit.

(8) We recommend that medical schools should provide an educational project toward the risk of smoking.

(9) It is recommended to provide a free or an affordable help for those who are willing to quite cigarette smoking. The mass media will play a major role of help in the control of this habit through the explanation of the bad squally of smoking. In addition posters, magazines, personal interview\& educational advice.

(10) We recommend encouraging the role of the family by providing an educational program to the parents so they will be able to deal with their children in the proper way.
(11) We recommend providing affordable group therapies for those who are willing to quit smoking.

(12) We recommend providing affordable alternatives to cigarette smoking like the electronic cigarette \& nicotine patches.

\section{References}

[1] Abdulghani HM, Alrowais NA, Alhaqwi AI, Alrasheedi A, AlZahir M, Al-Madani A, Al-Eissa A, Al-Hakmi B, Takroni R, Ahmad F. Cigarette smoking among female students in five medical and nonmedical colleges. International Journal of General Medicine. 6: 719-727, 2013.

[2] Abdulfatah SO. Smoking Kills Yearly 2.5 Million World Wide. The Somaliland times. 2003. http://somalilandtimes.net/2003/71/7108.shtml.

[3] Behan D F, Eriksen M P, Lin Y. Economic effects of environmental tobacco smoke. Society of Actuaries, 2005.

[4] BirknerFE, Kunze M. Smoking patterns at a British and at an American school. Med Educ. 12: 128-132, 1978.

[5] Brenner H, Scharrer S. Smoking habits of future physicians: a survey among medical students of a south German university. Soz Praventivmed. 41 (3): 150-7, 1996. PMID: 8767210 [PubMedindexed for MEDLINE].

[6] Coe RM, Cohen JD. Cigarette smoking among medical students. American Journal of Public Health. 70 (2): 169-171, 1980. PMCID: PMC1619194.

[7] Centers for Disease Control and Prevention. Current Cigarette Smoking Among Adults-United States, 2011. Morbidity and Mortality Weekly Report; 61 (44): 889-94. 2012.

[8] Centers for Disease Control and Prevention. Annual SmokingAttributable Mortality, Years of Potential Life Lost, and Economic Costs-United States, 1995-1999. Morbidity and Mortality Weekly Report; 51 (14): 300-3. 2002.

[9] Centers for Disease Control and Prevention. Annual SmokingAttributable Mortality, Years of Potential Life Lost, and Productivity Losses-United States, 2000-2004. Morbidity and Mortality Weekly Report; 57 (45): 1226-8. 2008.

[10] Centers for Disease Control and Prevention. National Center for Chronic Disease Prevention and Health Promotion. Tobacco Information and Prevention Source (TIPS). Tobacco Use in the United States. January 27, 2004.

[11] Centers for Disease Control and Prevention. Vital Signs: Current Cigarette Smoking Among Adults Aged $\geq 18$ Years-United States, 2005-2010. Morbidity and Mortality Weekly Report; 60 (33): 1207-12. 2011.

[12] Centers for Disease Control and Prevention. Smoking-Attributable Mortality, Years of Potential Life Lost, and Productivity LossesUnited States, 2000-2004. Morbidity and Mortality Weekly Report 57 (45): 1226-8. 2008.

[13] Centers for Disease Control and Prevention. Current Cigarette Smoking Among Adults-United States, 2011. Morbidity and Mortality Weekly Report 61 (44): 889-94. 2011.

[14] Davidson S., Haslet C., Chilvers E. \& Colledge N. Principle and practice of medicine. 19th Edition.

[15] El-Ansari W. Passive smoking in children: facts and public health implications, Eastern Mediterranean Health Journal. 8 (1), 2002.

[16] Foley WJ, Mc Ginn ME, Amoe HE, Jr, Coon WW, Culver DH. [Cigarette smoking among medical students]. N Engl J Med. 280 (23): 1284-1285. 1969 [PubMed].

[17] Jha P, Ramasundarahettige C, Landsman V, Rostron B, Thun M, Anderson RN, McAfee T, Peto R 21st Century Hazards of Smoking and Benefits of Cessation in the United States. New England Journal of Medicine. 368: 341-50, 2013.

[18] Najdawi, F. and Faouri, M. Maternal smoking and breastfeeding, Eastern Mediterranean Health Journal, 5 (3): 450-456, 1999.

[19] Nazary AA, Ahmadi F, Vaismoradi M, Kaviani K, Arezomandi M, Faghihzadeh S. Smoking among male medical sciences students in Semnan, Islamic Republic of Iran. Eastern Mediterranean health Joural. 16 (2): 156-161. 2010.

[20] Substance Abuse and Mental Health Administration. Results from the 2010 National Survey on Drug Use and Health: National Findings. Rockville (MD): Office of Applied Studies. 2010. 
[21] Smith DR, Leggat PA. An international review of tobacco smoking among medical students. Journal of Postgraduate Medicine; 53 (1): 55-62, 2007.

[22] Silverstein B, Feld S, Kozlouski LT. The availability of lownicotine cigarettes as a cause of cigarette smoking among teenage females. Journal of health and social behavior, Vol 21: 383-8. 1980.

[23] U.S. Department of Health and Human Services. How Tobacco Smoke Causes Disease: The Biology and Behavioral Basis for Smoking-Attributable Disease. Atlanta: U.S. Department of Health and Human Services, Centers for Disease Control and Prevention, National Center for Chronic Disease Prevention and Health Promotion, Office on Smoking and Health, 2010.

[24] U.S. Department of Health and Human Services. Preventing Tobacco Use Among Youth and Young Adults: A Report of the Surgeon General. Atlanta: U.S. Department of Health and Human Services, Centers for Disease Control and Prevention, Office on Smoking and Health, 2012.

[25] U.S. Department of Health and Human Services. The Health Consequences of Smoking: A Report of the Surgeon General. Atlanta: U.S. Department of Health and Human Services, Centers for Disease Control and Prevention, National Center for Chronic Disease Prevention and Health Promotion, Office on Smoking and Health, 2004

[26] Udall JA. Cigarette smoking among medical students. Curr Ther Res Clin Exp. 11 (5): 316-319. 1969 [PubMed].

[27] Thomas CB. Characteristics of smokers compared with nonsmokers in a population of healthy young adults, including observations on family history, blood pressure, heart rate, body weight, cholesterol and certain psychological traits. Ann Intern Med. Oct; 53: 697-718. 1960. [PubMed]

[28] Purvis JM, Smith DL. Smoking among medical students. South Med J. 69 (4): 413-416. 1976 [PubMed].

[29] Xinguang C, Xiaolan T, Bonita S, Hanwu L, Weiqing C. Cigarette smoking among medical students in China and modifiable risk factors for smoking prevention. Health Education, 112 (4), pp. 333-349. 2002.

[30] Xiang H, Wang Z, Stallones L, Yu S, Gimbel HW, Yang P. Cigarette smoking among medical college students in Wuhan, People's Republic of China. Preventive Medicine. 29 (3): 210-5. 1999. 